\title{
BMJ Open Identifying common baseline clinical features of COVID-19: a scoping review
}

\author{
Daniela Ferreira-Santos, ${ }^{1,2}$ Priscila Maranhão, ${ }^{1,2}$ Matilde Monteiro-Soares (iD , ${ }^{1,2}$ On \\ behalf of COVIDcids
}

To cite: Ferreira-Santos D, Maranhão P, Monteiro-Soares M. Identifying common baseline clinical features of COVID-19: a scoping review. BMJ Open 2020;10:e041079. doi:10.1136/ bmjopen-2020-041079

- Prepublication history for this paper is available online. To view these files, please visit the journal online (http://dx.doi. org/10.1136/bmjopen-2020041079).

Received 01 June 2020 Revised 06 August 2020 Accepted 11 August 2020

Check for updates

(c) Author(s) (or their employer(s)) 2020. Re-use permitted under CC BY-NC. No commercial re-use. See rights and permissions. Published by BMJ.

${ }^{1}$ CINTESIS - Center for Health Technology and Services Research, Faculty of Medicine, University of Porto, Porto, Portugal

${ }^{2}$ MEDCIDS - Departamento de Ciências da Informação e da Decisão em Saúde, Universidade do Porto, Porto, Portugal

Correspondence to Dr Daniela Ferreira-Santos; danielasantos@med.up.pt

\section{ABSTRACT}

Objectives Our research question was: what are the most frequent baseline clinical characteristics in adult patients with COVID-19? Our major aim was to identify common baseline clinical features that could help recognise adult patients at high risk of having COVID-19.

Design We conducted a scoping review of all the evidence available at LitCovid, until 23 March 2020.

Setting Studies conducted in any setting and any country were included.

Participants Studies had to report the prevalence of sociodemographic characteristics, symptoms and comorbidities specifically in adults with a diagnosis of infection by SARS-CoV-2.

Results In total, 1572 publications were published on LitCovid. We have included 56 articles in our analysis, with $89 \%$ conducted in China and $75 \%$ containing inpatients. Three studies were conducted in North America and one in Europe. Participants' age ranged from 28 to 70 years, with balanced gender distribution. The proportion of asymptomatic cases were from $2 \%$ to $79 \%$. The most common reported symptoms were fever (4\%-99\%), cough (4\%-92\%), dyspnoea/shortness of breath $(1 \%-90 \%)$, fatigue $(4 \%-89 \%)$, myalgia $(3 \%-65 \%)$ and pharyngalgia ( $2 \%-61 \%)$, while regarding comorbidities, we found cardiovascular disease $(1 \%-40 \%)$, hypertension $(0 \%-40 \%)$ and cerebrovascular disease $(1 \%-40 \%)$. Such heterogeneity impaired the conduction of meta-analysis. Conclusions The infection by COVID-19 seems to affect people in a very diverse manner and with different characteristics. With the available data, it is not possible to clearly identify those at higher risk of being infected with this condition. Furthermore, the evidence from countries other than China is, at the moment, too scarce.

\section{INTRODUCTION}

In December 2019, in Wuhan, Hubei Province, China, a cluster of patients with pneumonia of unknown cause was observed. ${ }^{1}$ Later, it was found that a new coronavirus caused it. In February 2020, the WHO designated the new virus as SARS-CoV-2 and the disease as COVID-19. According to this organisation, since the onset of this disease until 27 March 2020, SARS-CoV-2 has infected more than half a million people in 136 countries, leading to the death of $23335 .^{2}$

The identification of patients that might be infected is crucial so that they can

\section{Strength and limitations of this study}

This is the first scoping review addressing baseline clinical characteristics in adult patients with COVID-19.

- The authors followed the Preferred Reporting Items for Systematic reviews and Meta-Analyses extension for Scoping Reviews Checklist.

- Two researchers blindly and independently selected the studies and extracted data.

It was not possible to conduct a meta-analysis.

be adequately screened, treated and/or isolated. Political and health measures have been taken, having in consideration what is supposed to be known about populations at risk (focusing on their baseline comorbidities) and also identifying those that present a higher chance of being infected by COVID-19 (focusing on their clinical symptoms). However, clinical manifestations are highly variable, and the quality of the evidence that underlies these strategies and decisions is frequently not known. We consider that the creation of a predictive model that could help identify those at higher risk of having COVID-19, built on their baseline clinical features (such as sociodemographic, symptoms and presence of comorbidities), could help prioritise screening and therapeutic strategies. The first step to accomplishing such endeavour is to list the most pertinent variables to be included in such a model. For all this, we have conducted a scoping review to summarise and critically assess articles describing baseline characteristics of individuals infected with COVID-19.

\section{METHODS}

\section{Search strategy and selection criteria}

To conduct this scoping review, we used the Preferred Reporting Items for Systematic reviews and Meta-Analyses extension for Scoping Reviewer Checklist. ${ }^{3}$ 


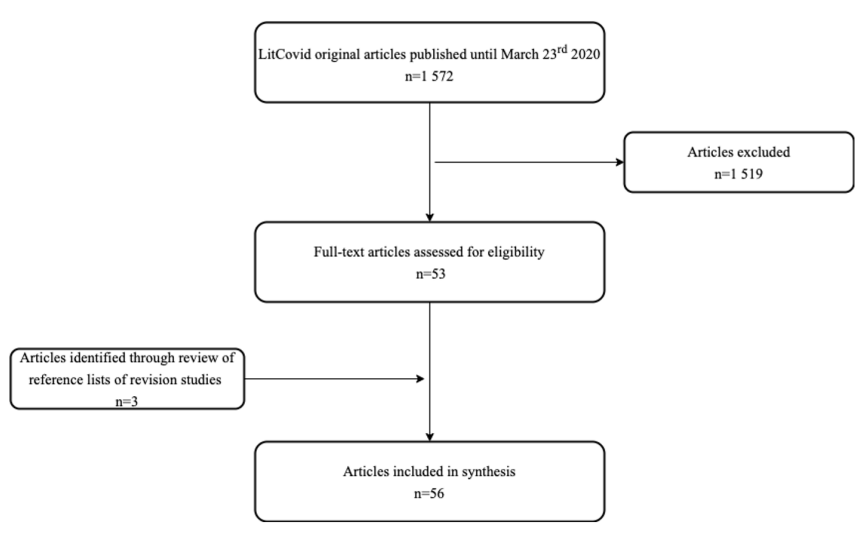

Figure 1 Articles' selection flow diagram.

We have used the Arksey and O'Malley methodological framework for conducting a scoping study consisting on the following stages: (1) identifying the research question, (2) identifying relevant studies, (3) study selection, (4) charting the data; and (5) collating, summarising and reporting results. ${ }^{4}$

To answer to the research question 'What are the most frequent baseline clinical characteristics (outcome) in adult patients with COVID-19 (population)?', we have reviewed all the evidence available on LitCovid ${ }^{5}$ for original articles published until 23 March 2020 in English, French, Italian, Spanish or Portuguese that reported the proportion of socio-demographic characteristics, symptoms and comorbidities in adults with COVID-19. LitCovid is a curated literature hub for tracking up-to-date scientific information about the 2019 novel coronavirus indexed and accessible through PubMed. This repository is considered the most comprehensive resource on the subject. We have excluded reviews, opinion articles, case series that included five or fewer patients, studies that included only pregnant women or children and clear data duplication studies.

\section{Data extraction}

Articles were selected by two of the authors independently (DF-S and PM) having in consideration the selection criteria. Once the articles were selected, data were extracted and charted (by one of the authors and checked by another) into an Excel spreadsheet and included the following information: date of publication, country of study conduction, the method used to detect the presence of COVID-19, last date of participants' inclusion, type of population, setting, sample size, participants' age and gender, frequency of asymptomatic patients and frequency of reported symptoms and comorbidities. We have ordered the included studies by continent, country (by alphabetical order) and sample size (in decreasing order). Only symptoms and comorbidities described by five or more studies were included in our tables. Those addressed by less than five studies were only described in the narrative synthesis.
Patient and public involvement

No patient involved.

\section{RESULTS}

\section{Characterisation of the included studies}

Until the defined date, there were 1572 publications in LitCovid and 53 (3\%) fulfilled the inclusion criteria. In total, 895 were opinion articles $(57 \%), 50(3 \%)$ had five or fewer participants included and the remaining addressed other topics such as diagnostic or genetics. We have used the reference list of $46(3 \%)$ retrieved review articles that had information on the frequency of symptoms to identify new articles that were not included in LitCovid database. This procedure led to the inclusion of three additional references. ${ }^{6-8}$ In total, we have included 56 studies, as we can see in figure 1.

In table 1 , we can see that, from the included studies, $50(89 \%)$ were from China. We were able to identify only two studies from USA, one from Canada, one from Korea, one from Singapore and one multicentre study that included patients from Belgium, Finland, France, Germany, Italy, Russia, Spain and Sweden. No study from Africa or Australia was retrieved.

The reverse transcription-PCR (RT-PCR) was the method most commonly used to detect the presence of infection by COVID-19 (89\%). Looking at the 51 studies that reported setting, two included patients that were seen in the emergency department, two admitted patients into intensive care unit due to COVID-19, four studies reported included outpatients, one incorporated outpatients and inpatients, while the remaining $(75 \%)$ included inpatients.

In total, 50500 participants were included. However, one of the studies from China ${ }^{9}$ contributed with $88 \%$ of the participants. Sample size ranged from 7 to 44672 participants, with a median of 66 participants per study.

The median age ranged from $28^{10}$ to $70 .{ }^{11}$ Both studies were conducted in North America. When looking at studies from other continents, we observe a smaller range. In Asia, median age varied from 33 years ${ }^{12}$ to 60 years, ${ }^{13}$ and 42 years in the European multicentre study. ${ }^{14}$ There was a balance on gender distribution, with the male gender proportion ranging from $44 \%{ }^{10}$ to $55 \%{ }^{15}$ in North American studies, $26 \%{ }^{8}$ to $77 \%{ }^{16}$ in Asian studies and $55 \%$ in the European study. ${ }^{14}$ In $57 \%$ of the studies, male gender was more prevalent.

Asymptomatic cases were reported in 10 studies (18\%), with no available data for North America. In the European study, ${ }^{14}$ there were $24 \%$ of asymptomatic patients and in Asia, it fluctuated from $2 \%^{917}$ to $79 \% .^{12}$

\section{Symptoms}

The described symptoms were generally non-specific and widely variable, ranging from asymptomatic to a rapid multiorgan dysfunction as we can see from tables 2-4.

Fever was one of the most reported symptoms. Its presence ranged from $48 \%{ }^{10}$ to $68 \%{ }^{15}$ in North America, from $4 \%^{18}$ to $99 \%$ in Asia and $69 \%$ in the European study. ${ }^{14}$ 


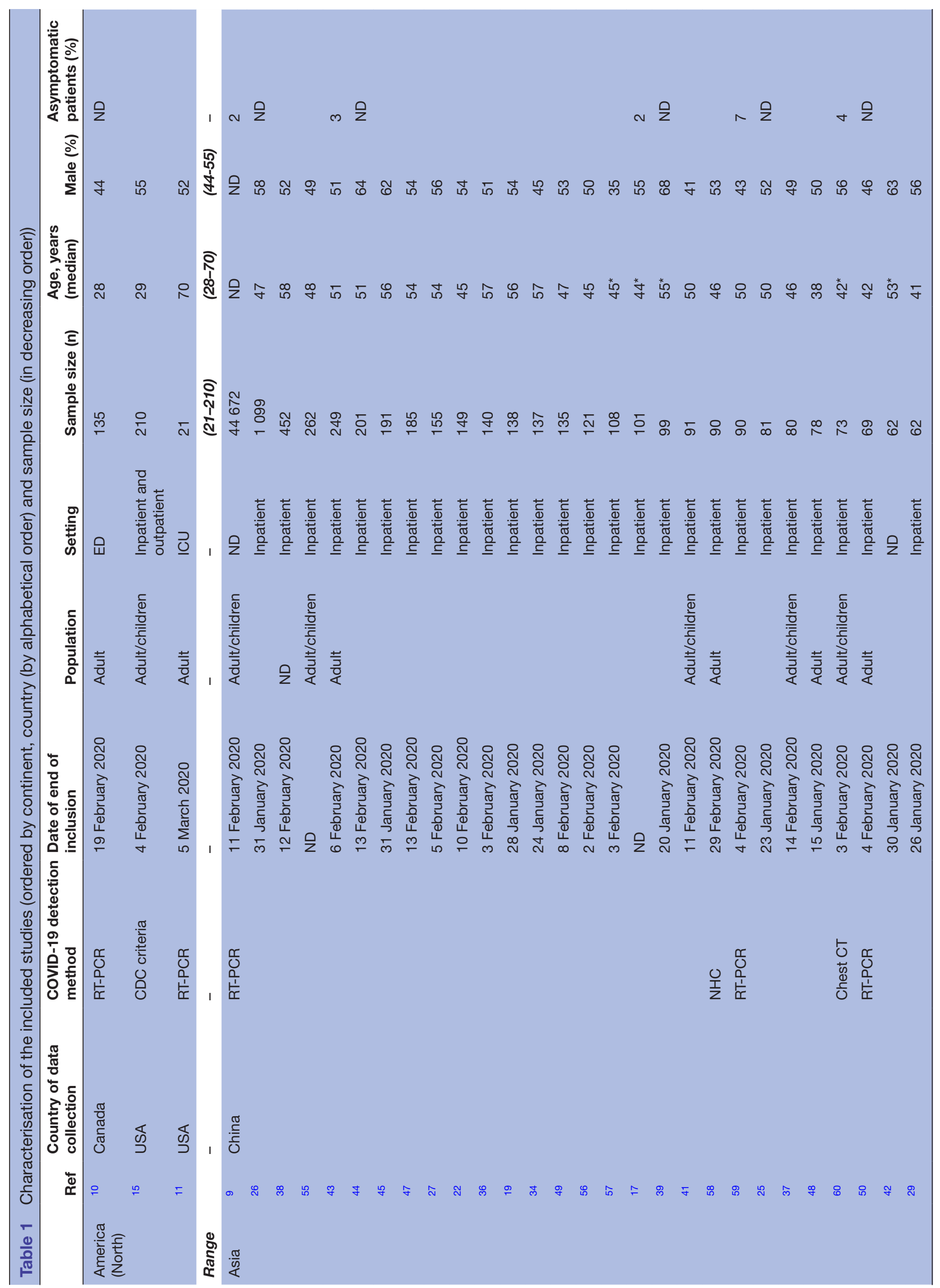




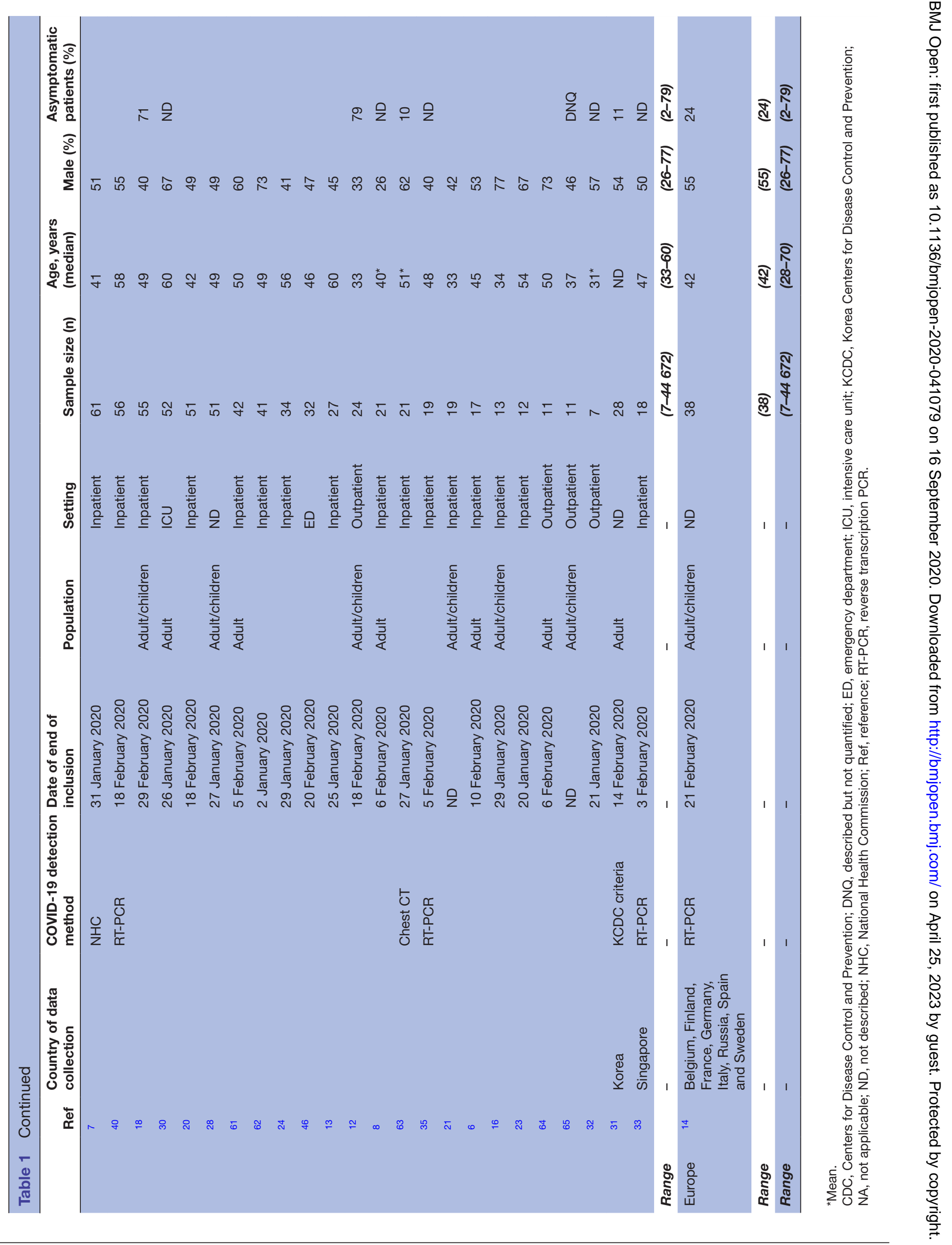




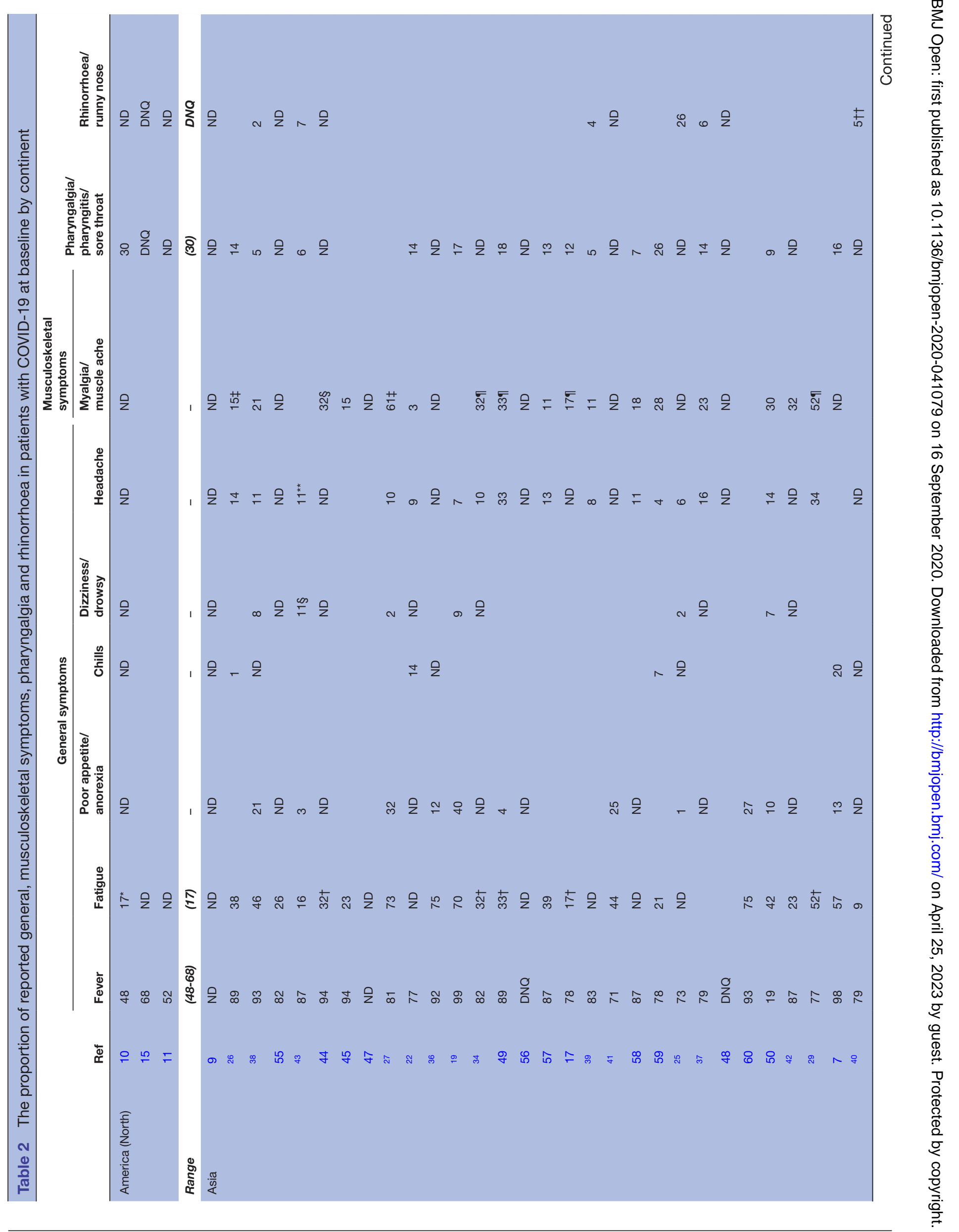




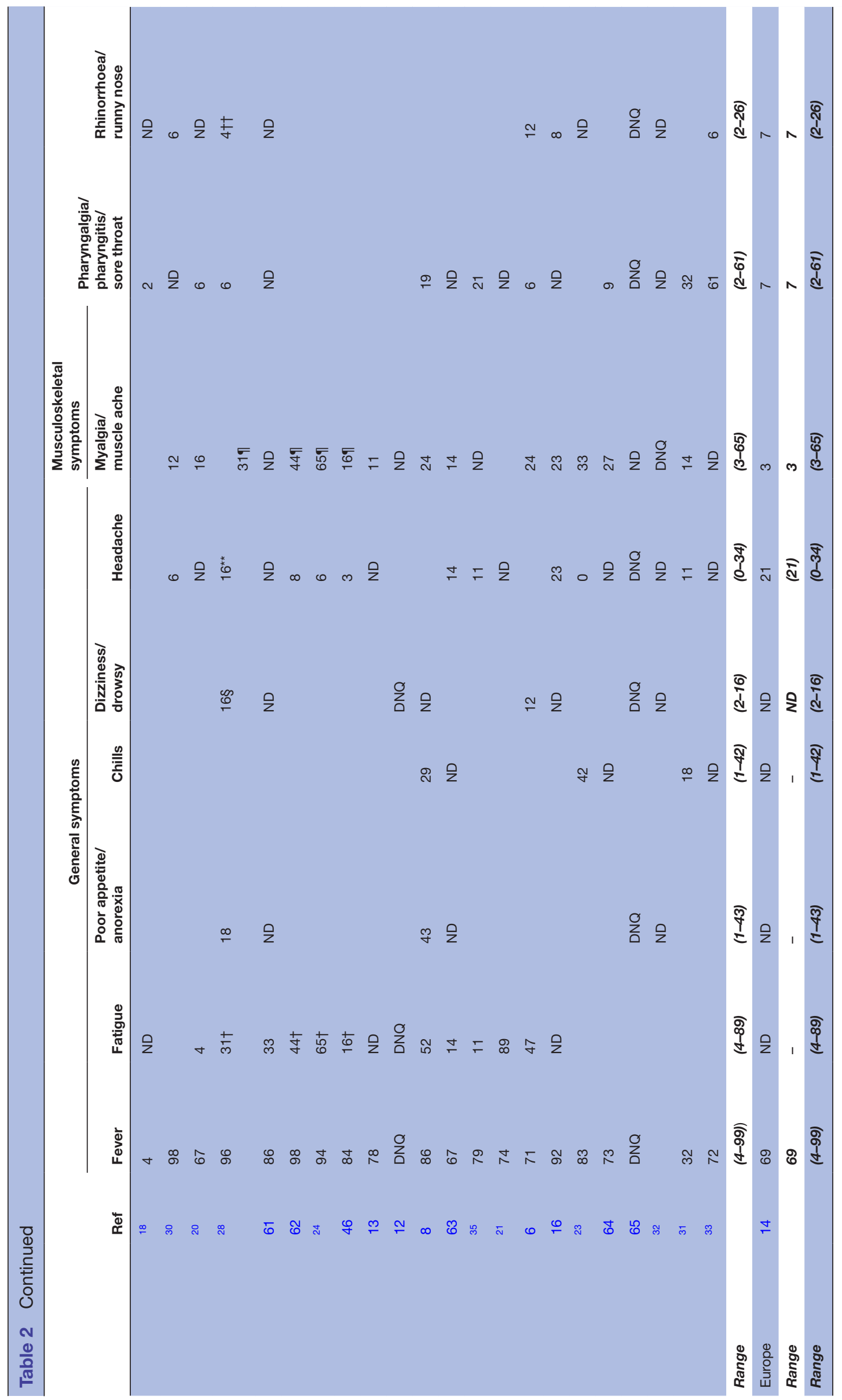


Table 3 The proportion of reported respiratory symptoms in patients with COVID-19 at baseline by continent

Respiratory symptoms

\begin{tabular}{|c|c|c|c|c|c|c|}
\hline & Reference & Cough & $\begin{array}{l}\text { Cough productive/ } \\
\text { expectoration/sputum }\end{array}$ & $\begin{array}{l}\text { Dyspnoea/ } \\
\text { shortness of breath }\end{array}$ & $\begin{array}{l}\text { Chest } \\
\text { tightness }\end{array}$ & $\begin{array}{l}\text { Chest } \\
\text { pain }\end{array}$ \\
\hline \multirow[t]{3}{*}{ America (North) } & 10 & $82^{*}$ & ND & $82 \dagger$ & ND & ND \\
\hline & 15 & $90^{*}$ & & $90 \dagger$ & & \\
\hline & 11 & 48 & & 76 & & \\
\hline Range & & (48-90) & - & (76-90) & - & - \\
\hline \multirow[t]{38}{*}{ Asia } & 9 & ND & ND & ND & ND & ND \\
\hline & 26 & 68 & 34 & 19 & & \\
\hline & 38 & 33 & 41 & 51 & & \\
\hline & 55 & 46 & ND & 7 & & \\
\hline & 43 & 37 & & 8 & & \\
\hline & 44 & 81 & & 40 & & \\
\hline & 45 & 79 & 23 & ND & & \\
\hline & 47 & ND & ND & & & \\
\hline & 27 & 63 & & 32 & & 4 \\
\hline & 22 & 58 & 32 & 1 & 11 & 3 \\
\hline & 36 & 75 & ND & 37 & 37 & ND \\
\hline & 19 & 59 & 27 & 31 & ND & \\
\hline & 34 & 48 & 4 & 19 & & \\
\hline & 49 & 77 & 9 & 13 & $9^{*}$ & \\
\hline & 56 & $\mathrm{DNQ}$ & $\mathrm{DNQ}$ & ND & ND & \\
\hline & 57 & 60 & ND & & & \\
\hline & 17 & 62 & & 1 & & \\
\hline & 39 & 82 & & 31 & & 2 \\
\hline & 41 & 60 & 33 & ND & & ND \\
\hline & 58 & 78 & 18 & 11 & & 6 \\
\hline & 59 & 63 & 12 & ND & & ND \\
\hline & 25 & 59 & 19 & 42 & 22 & \\
\hline & 37 & 64 & ND & 38 & ND & 4 \\
\hline & 48 & $\mathrm{DNQ}$ & & ND & & ND \\
\hline & 60 & 82 & 53 & & & \\
\hline & 50 & 55 & 29 & 29 & 20 & 9 \\
\hline & 42 & 45 & & 24 & ND & ND \\
\hline & 29 & 81 & 56 & ND & & \\
\hline & 7 & 64 & 44 & 12 & & 2 \\
\hline & 40 & 38 & & $7 \ddagger$ & $7^{\star}$ & ND \\
\hline & 18 & 4 & ND & ND & ND & \\
\hline & 30 & 77 & & 64 & & 2 \\
\hline & 20 & 45 & 25 & 8 & & ND \\
\hline & 28 & 47 & ND & $14 \S$ & & 14 * \\
\hline & 61 & 64 & & 19 & & ND \\
\hline & 62 & 76 & 28 & 55 & & \\
\hline & 24 & 50 & 24 & 15 & & \\
\hline & 46 & 66 & 16 & ND & 9 & \\
\hline
\end{tabular}

Continued 


\begin{tabular}{|c|c|c|c|c|c|c|}
\hline & \multirow[b]{2}{*}{ Reference } & \multicolumn{5}{|c|}{ Respiratory symptoms } \\
\hline & & Cough & $\begin{array}{l}\text { Cough productive/ } \\
\text { expectoration/sputum }\end{array}$ & $\begin{array}{l}\text { Dyspnoea/ } \\
\text { shortness of breath }\end{array}$ & $\begin{array}{l}\text { Chest } \\
\text { tightness }\end{array}$ & $\begin{array}{l}\text { Chest } \\
\text { pain }\end{array}$ \\
\hline & 12 & $\mathrm{DNQ}$ & & ND & & \\
\hline & 8 & 57 & 29 & & & 10 \\
\hline & 21 & 68 & & & ND & \\
\hline & 6 & 77 & 18 & & & \\
\hline & 16 & 46 & 15 & & & \\
\hline & 23 & 92 & ND & & & \\
\hline & 31 & 18 & & & & \\
\hline & 33 & 83 & ND & 11 & & \\
\hline Range & & (4-92) & $(4-56)$ & $(1-64)$ & $(5-37)$ & $(2-14)$ \\
\hline Europe & 14 & 48 & ND & 7 & ND & ND \\
\hline Range & & (48) & - & (7) & - & - \\
\hline Range & & (4-92) & $(4-56)$ & $(1-90)$ & $(5-37)$ & (2-14) \\
\hline
\end{tabular}

${ }^{*}$ Or dyspnoea.

tOr cough.

‡Or chest tightness.

$\S$ Or chest pain.

$\mathrm{DNQ}$, described but not quantified; ND, not described; Ref, reference.

Fatigue was observed in $17 \%$ of the participants from the USA study ${ }^{15}$ and ranged from $4 \%{ }^{20}$ to $89 \%{ }^{21}$ in studies from China. Myalgia was reported in $3 \%$ of the patients included in the European study. ${ }^{14}$ In Chinese studies, it ranged from $3 \%^{22}$ to $33 \%^{23}$ and reached $65 \%^{24}$ when combined with fatigue. Anorexia, chills and dizziness were registered only in Asian studies, and their prevalence ranged from $1 \%{ }^{25}$ to $43 \%,{ }^{8}$ from $1 \%^{26}$ to $42 \%{ }^{23}$ and from $2 \%{ }^{25} 27$ to $16 \%,{ }^{28}$ respectively. Complaints of headache were described in the European study in $21 \%^{14}$ of the patients and from $0 \%^{23}$ to $34 \%^{729}$ in two Chinese studies.

Malaise was present in $17 \%$ of the participants in one study from the $\mathrm{USA}^{10}$ and $35 \%$ in another study from Asia. ${ }^{30}$ Weakness was reported in $28 \%$ of patients in the European study ${ }^{14}$ and ranged from $9 \%^{25}$ to $11 \%{ }^{31}$ in two studies from China. Malnutrition was present in $2 \%$ of the participants in one study. ${ }^{30}$ Skin tingling was described but not quantified in one study. ${ }^{32}$ Arthralgia was described in three studies, all conducted in China. ${ }^{262730}$ This symptom was reported in $2 \%$ of the sample in one study, ${ }^{30}$ and $15 \%$ and $61 \%^{27}$ in two studies that combined the presence of arthralgia or myalgia as one symptom.

The presence of pharyngalgia was reported in one study from the USA, ${ }^{15}$ in $30 \%$ of the participants. In studies from China, the prevalence of this symptom varied from $2 \%{ }^{30}$ to $61 \% .{ }^{33}$ In the European study, ${ }^{14}$ both pharyngalgia and rhinorrhoea were reported by $7 \%$ of the participants. The later symptom ranged from $2 \%^{30}$ to $26 \%{ }^{25}$ in Chinese patients. The frequency of nasal congestion and throat congestion was reported only in studies from China. In one study, ${ }^{26} 2 \%$ of the participants described feeling throat congestion, and nasal congestion varied from $5 \%{ }^{26}$ to $62 \%^{16}$ in two studies.

From respiratory symptoms, the cough was the most frequently assessed; one study from the USA and European study reported to be present in $48 \%$ of the sample. ${ }^{11} 14$ Cough or dyspnoea was reported by $82 \%$ of the patients in one study from Canada ${ }^{10}$ and $90 \%$ in the USA. ${ }^{15}$ Specifically, productive cough, chest tightness and chest pain were registered only on studies from China and varied from $4 \%^{34}$ to $56 \%,{ }^{29}$ from $5 \%^{35}$ to $37 \%^{36}$ and $2 \%^{30}$ to $14 \%,{ }^{28}$ respectively. In one study, ${ }^{28} 14 \%$ of patients reported feeling chest pain or dyspnoea.

The presence of dyspnoea alone was also described in the majority of the studies. One study from the USA reported its presence in $76 \%$ of the patients, ${ }^{11}$ while in the European study, ${ }^{14}$ it was only observed in $7 \%$ of the patients. As for the studies conducted in China, dyspnoea prevalence oscillated from $1 \%{ }^{22}$ to $64 \% .^{30}$ 
Table 4 The proportion of reported gastrointestinal symptoms in patients with COVID-19 at baseline by continent

\begin{tabular}{llllll}
\hline & & \multicolumn{4}{c}{ Gastrointestinal symptoms } \\
\cline { 2 - 6 } & Reference & Diarrhoea & Nausea & Vomiting/emesis & Abdominal distress \\
\hline America (North) & 10 & ND & ND & ND & ND \\
& 15 & & & & \\
& 11 & & & & \\
& & & & &
\end{tabular}

\section{Range}

$-$

Asia

ND $\quad$ ND

$\begin{array}{ll}9 & \\ 26 & \\ 38 & \\ 55 & \\ 43 & \\ 44 & \\ 45 & 5 \\ 47 & 5 \\ 27 & 5 \\ 22 & 7\end{array}$

4

27

ND

3

ND

5

ND

5

7

13

10

8

13

49

56

57

17

39

41

58

59

25

37

48

60

50

42

29

7

40

18

30

20

28

61

62

24

46

13

12

14

3

23

14

$15^{*}$

8

10

ND

\section{3}

15

3

ND

-

ND

ND

5

9

5

ND

ND

4

ND

4

2

1

ND

17

10

6

5

2

ND

4

ND

3

ND

2

1

12

7

1

ND

ND

8†

6

2

ND

ND

5

1

ND

ND

4

ND

15†

8

ND

ND

6

ND

ND 


\begin{tabular}{|c|c|c|c|c|c|}
\hline & \multirow[b]{2}{*}{ Reference } & \multicolumn{4}{|c|}{ Gastrointestinal symptoms } \\
\hline & & Diarrhoea & Nausea & Vomiting/emesis & Abdominal distress \\
\hline & 8 & & & & \\
\hline & 35 & 5 & ND & & \\
\hline & 21 & 16 & & & \\
\hline & 16 & 8 & & & \\
\hline & 23 & 17 & 17 & & \\
\hline & 64 & 9 & ND & ND & \\
\hline & 65 & DNQ & & & \\
\hline & 32 & ND & & & \\
\hline Range & & $(1-27)$ & $(1-17)$ & $(1-18)$ & $(1-15)$ \\
\hline Europe & 14 & 3 & 3 & ND & ND \\
\hline Range & & (3) & (3) & - & - \\
\hline Range & & $(1-27)$ & $(1-17)$ & $(1-18)$ & $(1-15)$ \\
\hline
\end{tabular}

*Or dyspnoea.

tOr cough.

‡Or chest tightness.

§Or chest pain.

DNQ, described but not quantified; ND, not described; Ref, reference.

General gastrointestinal symptoms were described by $10 \%{ }^{10}$ of the patients in one study from Canada and $40 \%{ }^{36}$ in another from China. From the gastrointestinal system, only diarrhoea and nausea were recorded in the European study. ${ }^{14}$ Both presented a $3 \%$ prevalence. From the studies conducted in China, diarrhoea prevalence ranged from $1 \%^{37}$ to $27 \%,{ }^{38}$ nausea from $1 \%^{223739}$ to $17 \%,{ }^{23}$ vomit from $1 \%{ }^{30}$ to $18 \%{ }^{40}$ and abdominal distress from $1 \%{ }^{41}$ to $6 \% .{ }^{36}$ When combining abdominal pain or diarrhoea, the prevalence raised to $15 \% .{ }^{42}$ Belching or gastritis was recorded in only one study from China ${ }^{36}$ and was reported by $5 \%$ of the patients. Irritability or confusion was documented in $3 \%{ }^{22}$ and $9 \%{ }^{39}$ of the patients included in two studies from China, and the presence of rash and enlargement of lymph nodes was assessed in only one study and was not found in any patient. ${ }^{26}$

\section{Comorbidities}

As we can see in table 5, the presence of comorbidities was not reported in the European study, and only one of the studies from the USA had relevant information. ${ }^{11}$ In this study, $86 \%$ of the patients had at least one comorbidity. The most frequent were chronic kidney disease (48\%), congestive heart failure (43\%), diabetes $(33 \%)$, chronic obstructive pulmonary disease $(33 \%)$ and obstructive sleep apnoea $(29 \%)$. Less than $10 \%$ of the patients presented end-stage kidney disease, asthma, cirrhosis and rheumatological disease.
The remaining data were from Asian studies, in which several concomitant infections were described. The presence of hepatitis B was observed in $1 \%,{ }^{43} 2 \%{ }^{18}{ }^{26}$ and $5 \%$ of the participants in the four studies that described its frequency. Prevalence of HIV was reported to be of $0 \%{ }^{19} 2737$ and $6 \% .{ }^{24}$ Only one study described bacterial coinfection in $17 \%$ of the patients. ${ }^{23}$

Numerous studies described that some patients presented malignant diseases. This comorbidity prevalence ranged from $0 \%{ }^{43}$ up to $9 \% .{ }^{24}$ Only one study described the presence of thyroid disease ${ }^{36}$ and other of hyperlipidaemia in $4 \%$ and $5 \%^{36}$ of the participants, respectively. Two studies reported the presence of hypothyroidism in $2 \%$ and $6 \%^{24}$ of the patients. Various studies reported the prevalence of diabetes, with values ranging from $2 \%{ }^{44}$ up to $33 \%{ }^{45}$ The presence of kidney disease ranged from $1 \%^{92645}$ up to $6 \%^{20}$; chronic kidney disease was observed in $1 \%^{36}$ up to $17 \%^{25}$ of the patients. Only one study reported the proportion of patients with renal insufficiency ${ }^{23}$ and urolithiasis ${ }^{36}$ to be of $17 \%$ and $2 \%$, respectively. Chronic liver disease was observed in $0 \%^{23}$ to $11 \%^{29}$ of the participants. Hepatic insufficiency was reported by two studies to have a prevalence of $9 \%{ }^{25}$ and $17 \% .{ }^{23}$ Fatty liver and abnormal liver function were observed in $6 \%$ of the patients in one study. ${ }^{36}$ Digestive system diseases were described in four studies in $4 \%,{ }^{43}$ $6 \%{ }^{17}$ and $11 \%^{39}$ of the participants. 


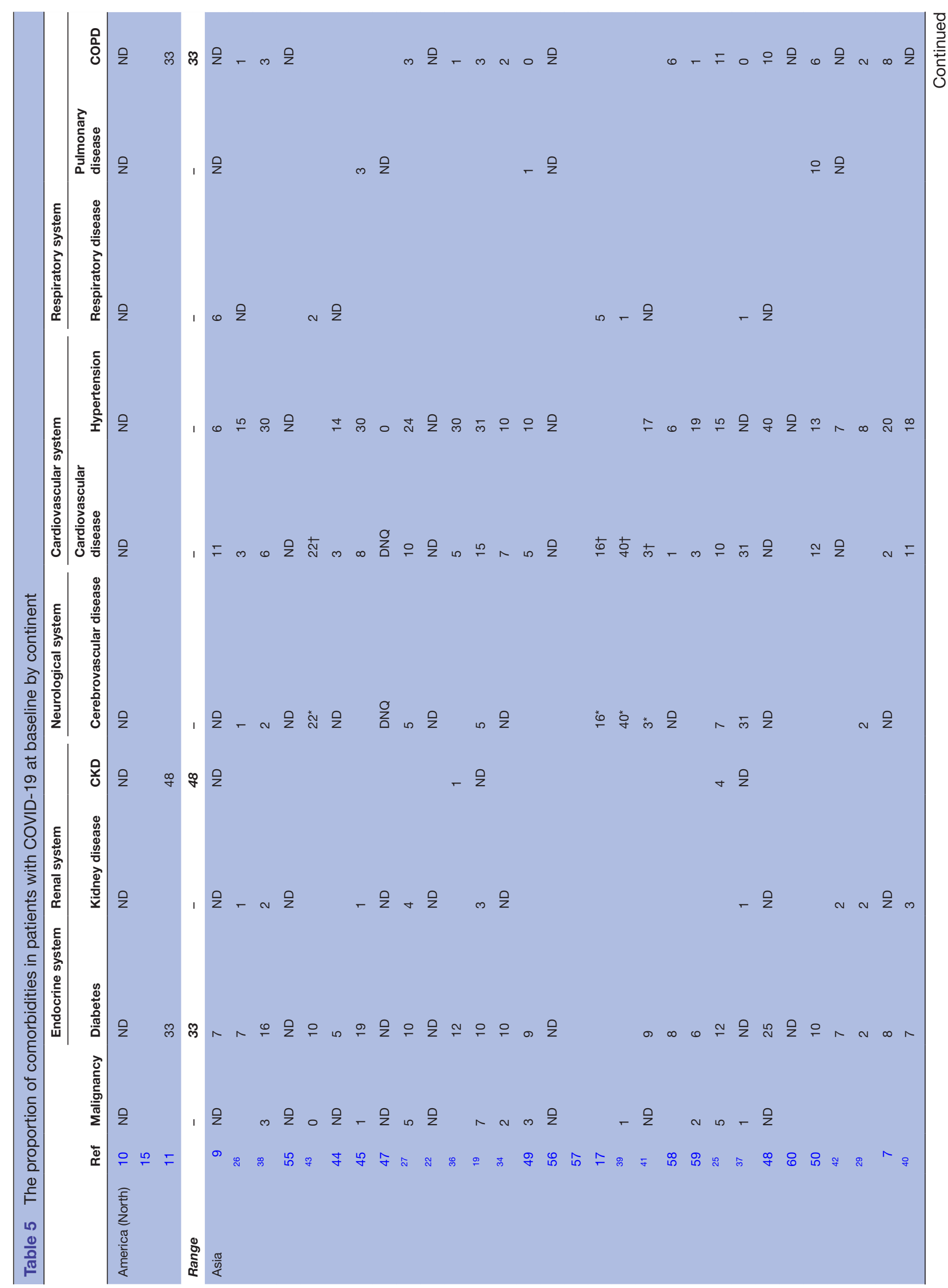




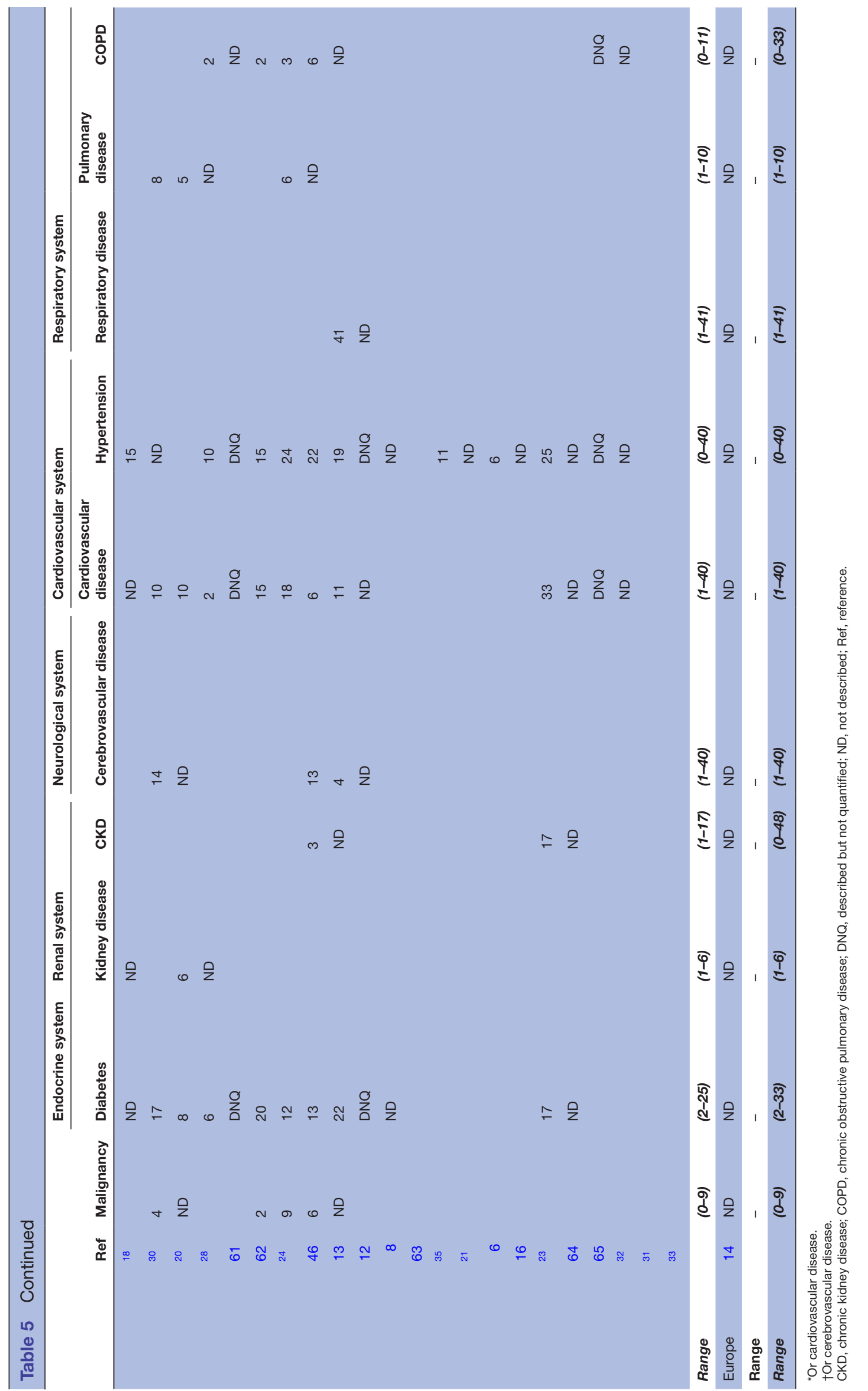


The presence of cerebrovascular disease was reported in several studies and ranged from $1 \%^{26}$ to $31 \%^{37}$ of the participants, reaching $40 \%{ }^{39}$ when combined with cardiovascular disease. Dementia was described in one study, with a value of $2 \% .^{30}$ Nervous system diseases were ascertained in three studies, with a frequency of $1 \%^{3739}$ and $3 \%{ }^{46}$ The same number of studies registered history of stroke and observed its presence in $2 \%^{3642}$ and $8 \%^{23}$ of the participants.

Cardiovascular disease prevalence ranged from $1 \%^{728}$ to $33 \%{ }^{23}$ of the patients in the various studies reporting it. Hypertension frequency varied from $0 \%{ }^{47}$ to $40 \%{ }^{48}$ The presence of tachycardia was registered in four studies and reported to be of $2 \%,{ }^{7} 4 \%^{49}$ and $7 \% .{ }^{34}{ }^{50}$ We only found one study that described the prevalence of arrhythmia (with a value of $4 \%^{36}$ ), persistent atrial fibrillation $\left(6 \%{ }^{40}\right.$ ), cardiac failure $\left(8 \%^{23}\right)$ or aorta sclerosis $\left(1 \%^{36}\right)$.

Various studies described the prevalence of baseline respiratory system conditions. Respiratory disease, in general, was found in $1 \%^{37} 39$ to $41 \%^{13}$ of the patients, pulmonary disease to range between $1 \%^{49}$ and $10 \%^{50}$ and chronic obstructive pulmonary disease between $0 \%{ }^{24} 50$ and $33 \%{ }^{50}$ of the patients. We only found two studies that described the prevalence of asthma (with a value of $2 \%{ }^{18}$ up to $9 \%{ }^{11}$ ), and one study describing a $6 \%$ of rhinitis. ${ }^{6}$

\section{DISCUSSION}

This is the first scoping review focusing on baseline characteristics of patients with COVID-19. Although we aimed to try to better identify those at higher risk of having the condition, only descriptive studies were found. We have identified 56 articles; two were conducted in the USA, one in Canada and one was a multicentre European study. No studies from Africa, South America or Australia were retrieved. At the date of the end of our review, according to $\mathrm{WHO},{ }^{51}$ there were 25375 cases of COVID-19 in the region of the Americas, 171424 in European region and 990 in African region.

As we can observe above, most of the studies were conducted in China, the first country in which COVID-19 was detected. Furthermore, one of these studies ${ }^{9}$ contributed to $88 \%$ of the participants. This study consists of the Chinese Centre for Disease Control and Prevention Report. Therefore, we cannot be sure about how many of the other Chinese studies described results that are included in this report, representing duplicate participants.

We observed a very high heterogeneity on sample size, patients' age and described symptoms and comorbidities. Accounting for this heterogeneity, we have considered that it was not adequate to conduct a meta-analysis and performed only a narrative synthesis of the available evidence. We also acknowledge the exclusion of articles written only in Chinese due to the fear of further data duplication $^{52}$ and the exponential growth of published evidence about COVID-19 since our review.
In the included studies, the median age ranged from 28 to 70 years, being 50 years or less in $36(72 \%)$ of the studies. Only one-fifth of the studies described the proportion of asymptomatic patients. In the European study, it was around $25 \%$, and in the Asian studies, it ranged from $2 \%$ up to $75 \%$ of the patients. It highlights the importance of wide screening and people isolation strategies due to the risk of being in contact with infected but asymptomatic people.

The prevalence of more than 30 symptoms and 35 comorbidities were collected; however, several were reported by five or fewer studies. The most reported symptoms were fever, cough, dyspnoea, fatigue, myalgia and pharyngalgia. Cardiovascular disease, hypertension and cerebrovascular disease were the most reported comorbidities. However, this is also due to the commonly high prevalence of these diseases in the general population and the focus given to more severe cases by several studies.

There is a previous systematic review with metaanalysis of the prevalence of symptoms and comorbidities in people with COVID-19 that included eight studies published until 5 February $2020 .^{53}$ The authors concluded that the most prevalent clinical symptoms were fever (with a pooled prevalence of $91 \%$ ), cough (67\%), fatigue $(51 \%)$ and dyspnoea $(30 \%)$. The most prevalent comorbidities were hypertension (17\%), diabetes $(8 \%)$, cardiovascular diseases $(5 \%)$ and respiratory system diseases $(2 \%)$. However, the authors reported high levels of heterogeneity when pooling such prevalence $\left(\mathrm{I}^{2}\right.$ ranged from $85 \%$ to $96 \%$ ).

A more recent systematic review with meta-analysis to identify clinical, laboratory and imaging features of COVID-19, included studies until 21 February 2020. ${ }^{54}$ When pooling the 18 included studies, once again, fever (pooled prevalence of $88 \%$ ), cough $(58 \%)$ and dyspnoea were the most common symptoms, and hypertension $(19 \%)$, cardiovascular disease $(14 \%)$ and diabetes $(12 \%)$ were the most frequent comorbidities. Once again, severe heterogeneity was observed by the authors.

Our study observed that the presence of fever ranged from four to $99 \%$, cough from $4 \%$ to $92 \%$, fatigue from $4 \%$ to $89 \%$ and dyspnoea from $1 \%$ to $90 \%$; as for comorbidities, the prevalence of hypertension varied from $0 \%$ to $40 \%$, diabetes from $2 \mathrm{p} \%$ to $33 \%$ and cardiovascular disease from $1 \%$ to $40 \%$. We highlight that these values cannot be directly compared between studies without having in consideration that they reflect the existence of different populations, healthcare settings, selection criteria and different times of the disease history. Such massive variation on the range of observed prevalence for all symptoms and comorbidities impairs the selection of any of them as pertinent to be included in a predictive model to identify people at high risk of being infected with COVID-19.

We consider that future research conducted specifically with that aim and assessing the ability of several symptoms and/or comorbidities combined to stratify people by 
their risk of being infected is crucial. Also, there is a great need for further studies conducted outside China so that comparisons can be made about baseline characteristics as well as clinical outcomes.

Acknowledgements We also would like to acknowledge Professor Pedro Pereira Rodrigues and M.D. Ana Margarida Pereira, for a critical review of the manuscript.

Contributors DF-S and MM-S designed the work. DF-S and PM extracted data from the articles. All authors screened the article, analysed and interpreted data, produced and revised all important intellectual content and gave their final approval of the version to be published and agreed to be accountable for all aspects of the work in ensuring that questions related to the accuracy or integrity of any part of the work are appropriately investigated and resolved.

Funding The work from DF-S was supported by Fundacão para a Ciência e Tecnologia (grant number PD/BD/13553/2018). The work from PM was supported by ODISSEIA - Oncology Information System project (POCI-05-5762-FSE-039021), financed by the North Portugal Regional Operational Programme (NORTE 2020), under the PORTUGAL 2020 Partnership Agreement, and through the European Regional Development Fund and European Social Fund, respectively.

Competing interests None declared.

Patient and public involvement Patients and/or the public were not involved in the design, or conduct, or reporting, or dissemination plans of this research.

Patient consent for publication Not required.

Provenance and peer review Not commissioned; externally peer reviewed.

Data availability statement Data sharing not applicable as no datasets generated and/or analysed for this study. Data sharing not applicable.

Open access This is an open access article distributed in accordance with the Creative Commons Attribution Non Commercial (CC BY-NC 4.0) license, which permits others to distribute, remix, adapt, build upon this work non-commercially, and license their derivative works on different terms, provided the original work is properly cited, appropriate credit is given, any changes made indicated, and the use is non-commercial. See: http://creativecommons.org/licenses/by-nc/4.0/.

ORCID iD

Matilde Monteiro-Soares http://orcid.org/0000-0002-4586-2910

\section{REFERENCES}

1 Wang C, Horby PW, Hayden FG, et al. A novel coronavirus outbreak of global health concern. Lancet 2020;395:470-3.

2 WHO. Coronavirus disease 2019 (COVID 2019): situation report, 2020.

3 Tricco AC, Lillie E, Zarin W, et al. PRISMA extension for scoping reviews (PRISMA-ScR): checklist and explanation. Ann Intern Med 2018;169:467-73.

4 Arksey H, O'Malley L. Scoping studies: towards a methodological framework. Int J Soc Res Methodol 2005;8:19-32.

5 LitCovid. LitCovid, 2020. Available: https://www.ncbi.nlm.nih.gov/ research/coronavirus/

$6 \mathrm{Li} \mathrm{J,} \mathrm{Li} \mathrm{S,} \mathrm{Cai} \mathrm{Y,} \mathrm{et} \mathrm{al.} \mathrm{Epidemiological} \mathrm{and} \mathrm{clinical} \mathrm{characteristics}$ of 17 hospitalized patients with 2019 novel coronavirus infections outside Wuhan, China medRxiv 2020.

7 Liu J, Liu Y, Xiang P, et al. Neutrophil-to-Lymphocyte ratio predicts critical illness patients with 2019 coronavirus disease in the early stage. J Trans/ Med 2020;18:206.

8 Pan F, Ye T, Sun P, et al. Time course of lung changes on chest CT during recovery from 2019 novel coronavirus (COVID-19) pneumonia. Radiology 2020:200370.

9 Wu Z, McGoogan JM. Characteristics of and important lessons from the coronavirus disease 2019 (COVID-19) outbreak in China: summary of a report of 72314 cases from the Chinese center for disease control and prevention. JAMA 2020.

10 Lin M, Beliavsky A, Katz K, et al. What can early Canadian experience screening for COVID-19 teach us about how to prepare for a pandemic? CMAJ 2020;192:E314-8.

11 Arentz M, Yim E, Klaff L, et al. Characteristics and outcomes of 21 critically ill patients with COVID-19 in Washington state. JAMA 2020. doi:10.1001/jama.2020.4326. [Epub ahead of print: 19 Mar 2020].
$12 \mathrm{Hu}$ Z, Song C, Xu C, et al. Clinical characteristics of 24 asymptomatic infections with COVID-19 screened among close contacts in Nanjing, China. Sci China Life Sci 2020;63:706-11.

13 Yuan M, Yin W, Tao Z, et al. Association of radiologic findings with mortality of patients infected with 2019 novel coronavirus in Wuhan, China. PLoS One 2020;15:e0230548.

14 Spiteri G, Fielding J, Diercke M, et al. First cases of coronavirus disease 2019 (COVID-19) in the who European region, 24 January to 21 February 2020. Euro Surveill 2020;25.

15 Bajema KL, Oster AM, McGovern OL, et al. Persons Evaluated for 2019 Novel Coronavirus - United States, January 2020. MMWR Morb Mortal Wkly Rep 2020;69:166-70.

16 Chang D, Lin M, Wei L, et al. Epidemiologic and clinical characteristics of novel coronavirus infections involving 13 patients outside Wuhan, China. JAMA 2020;323:1092-3.

17 Zhao W, Zhong Z, Xie X, et al. Relation between chest CT findings and clinical conditions of coronavirus disease (COVID-19) pneumonia: a multicenter study. AJR Am J Roentgenol 2020;214:1072-7.

18 Wang Y, Liu Y, Liu L, et al. Clinical outcomes in 55 patients with severe acute respiratory syndrome coronavirus 2 who were asymptomatic at hospital admission in Shenzhen, China. J Infect Dis 2020;221:1770-4.

19 Wang D, Hu B, Hu C, et al. Clinical characteristics of 138 hospitalized patients with 2019 novel coronavirus-infected pneumonia in Wuhan, China. JAMA 2020. doi:10.1001/jama.2020.1585. [Epub ahead of print: 07 Feb 2020].

$20 \mathrm{Xu} \mathrm{T}$, Chen C, Zhu Z, et al. Clinical features and dynamics of viral load in imported and non-imported patients with COVID-19. Int $J$ Infect Dis 2020;94:68-71.

21 Xie C, Jiang L, Huang G, et al. Comparison of different samples for 2019 novel coronavirus detection by nucleic acid amplification tests. Int J Infect Dis 2020;93:264-7.

22 Yang W, Cao Q, Qin L, et al. Clinical characteristics and imaging manifestations of the 2019 novel coronavirus disease (COVID19):A multi-center study in Wenzhou city, Zhejiang, China. J Infect 2020;80:388-93.

23 Liu Y, Yang Y, Zhang C, et al. Clinical and biochemical indexes from 2019-nCoV infected patients linked to viral loads and lung injury. Sci China Life Sci 2020;63:364-74.

24 Huang Y, Tu M, Wang S, et al. Clinical characteristics of laboratory confirmed positive cases of SARS-CoV-2 infection in Wuhan, China: a retrospective single center analysis. Travel Med Infect Dis 2020;101606:101606.

25 Shi $\mathrm{H}$, Han X, Jiang $\mathrm{N}$, et al. Radiological findings from 81 patients with COVID-19 pneumonia in Wuhan, China: a descriptive study. Lancet Infect Dis 2020;20:425-34.

26 Guan WJ, ZY N, Hu Y, et al. Clinical characteristics of coronavirus disease 2019 in China. N Engl J Med 2020.

27 Mo P, Xing Y, Xiao Y, et al. Clinical characteristics of refractory COVID-19 pneumonia in Wuhan, China. Clin Infect Dis 2020. doi:10.1093/cid/ciaa270. [Epub ahead of print: 16 Mar 2020].

28 Song F, Shi N, Shan F, et al. Emerging 2019 novel coronavirus (2019nCoV) pneumonia. Radiology 2020;295:210-7.

$29 \mathrm{Xu} \mathrm{X-W,} \mathrm{Wu} \mathrm{X-X,} \mathrm{Jiang} \mathrm{X-G,} \mathrm{et} \mathrm{al.} \mathrm{Clinical} \mathrm{findings} \mathrm{in} \mathrm{a} \mathrm{group}$ of patients infected with the 2019 novel coronavirus (SARSCov-2) outside of Wuhan, China: retrospective case series. BMJ 2020;368:m606.

30 Yang $\mathrm{X}, \mathrm{Yu} \mathrm{Y}, \mathrm{Xu} \mathrm{J}$, et al. Clinical course and outcomes of critically ill patients with SARS-CoV-2 pneumonia in Wuhan, China: a singlecentered, retrospective, observational study. Lancet Respir Med 2020;8:475-81.

31 COVID-19 National Emergency Response Center, Epidemiology and Case Management Team, Korea Centers for Disease Control and Prevention. Early epidemiological and clinical characteristics of 28 cases of coronavirus disease in South Korea. Osong Public Health Res Perspect 2020;11:8-14.

32 Tong Z-D, Tang A, Li K-F, Zhen-Dong T, An T, Ke-Feng L, et al. Potential presymptomatic transmission of SARS-CoV-2, Zhejiang Province, China, 2020. Emerg Infect Dis 2020;26:1052-4.

33 Young BE, Ong SWX, Kalimuddin S, et al. Epidemiologic features and clinical course of patients infected with SARS-CoV-2 in Singapore. JAMA 2020. doi:10.1001/jama.2020.3204. [Epub ahead of print: 03 Mar 2020].

34 Liu K, Fang Y-Y, Deng Y, et al. Clinical characteristics of novel coronavirus cases in tertiary hospitals in Hubei Province. Chin Med J 2020;133:1025-31.

35 Zhao D, Yao F, Wang L, et al. A comparative study on the clinical features of coronavirus 2019 (COVID-19) pneumonia with other pneumonias. Clin Infect Dis 2020;71:756-61. 
36 Zhang J-J, Dong X, Cao Y-Y, et al. Clinical characteristics of 140 patients infected with SARS-CoV-2 in Wuhan, China. Allergy 2020;75:1730-41.

37 Wu J, Liu J, Zhao X, et al. Clinical characteristics of imported cases of coronavirus disease 2019 (COVID-19) in Jiangsu Province: a multicenter descriptive study. Clin Infect Dis 2020;71:706-12.

38 Qin C, Zhou L, Hu Z, et al. Dysregulation of immune response in patients with coronavirus 2019 (COVID-19) in Wuhan, China. Clin Infect Dis 2020;71:762-768.

39 Chen N, Zhou M, Dong X, et al. Epidemiological and clinical characteristics of 99 cases of 2019 novel coronavirus pneumonia in Wuhan, China: a descriptive study. Lancet 2020;395:507-13.

40 Liu K, Chen Y, Lin R, et al. Clinical features of COVID-19 in elderly patients: a comparison with young and middle-aged patients. $J$ Infect 2020:80:e14-18.

41 Qian G-Q, Yang N-B, Ding F, et al. Epidemiologic and clinical characteristics of 91 hospitalized patients with COVID-19 in Zhejiang, China: a retrospective, multi-centre case series. QJM 2020;113:474-81.

42 Zhou S, Wang Y, Zhu T, et al. CT features of coronavirus disease 2019 (COVID-19) pneumonia in 62 patients in Wuhan, China. AJR Am J Roentgenol 2020;214:1287-94.

43 Chen J, Qi T, Liu L, et al. Clinical progression of patients with COVID-19 in Shanghai, China. J Infect 2020;80:e1-6.

44 Wu C, Chen X, Cai Y, et al. Risk factors associated with acute respiratory distress syndrome and death in patients with coronavirus disease 2019 pneumonia in Wuhan, China. JAMA Intern Med 2020. doi:10.1001/jamainternmed.2020.0994. [Epub ahead of print: 13 Mar 2020].

45 Zhou F, Yu T, Du R, et al. Clinical course and risk factors for mortality of adult inpatients with COVID-19 in Wuhan, China: a retrospective cohort study. Lancet 2020;395:1054-62.

46 Zhu W, Xie K, Lu H, et al. Initial clinical features of suspected coronavirus disease 2019 in two emergency departments outside of Hubei, China. J Med Virol.

47 Tang N, Li D, Wang X, et al. Abnormal coagulation parameters are associated with poor prognosis in patients with novel coronavirus pneumonia. J Thromb Haemost 2020;18:844-7.

48 Liu W, Tao Z-W, Wang L, et al. Analysis of factors associated with disease outcomes in hospitalized patients with 2019 novel coronavirus disease. Chin Med J 2020;133:1032-8.

49 Wan S, Xiang Y, Fang W, et al. Clinical features and treatment of COVID-19 patients in northeast Chongqing. J Med Virol 2020;92:797-806.

50 Wang Z, Yang B, Li Q, et al. Clinical features of 69 cases with coronavirus disease 2019 in Wuhan, China. Clin Infect Dis 2020;71:769-77.
51 WHO. Coronavirus disease 2019 (COVID-19) situation report 63, 2020. Available: https://www.who.int/docs/default-source/ coronaviruse/situation-reports/20200323-sitrep-63-covid-19.pdf? sfvrsn=d97cb6dd 2

52 Li B, Yang J, Zhao F, et al. Prevalence and impact of cardiovascular metabolic diseases on COVID-19 in China. Clin Res Cardiol 2020;109:1-8:531-8

53 Yang J, Zheng Y, Gou X, et al. Prevalence of comorbidities and its effects in patients infected with SARS-CoV-2: a systematic review and meta-analysis. Int J Infect Dis 2020;94:91-5.

54 Rodriguez-Morales AJ, Cardona-Ospina JA, Gutiérrez-Ocampo E, et al. Clinical, laboratory and imaging features of COVID-19: a systematic review and meta-analysis. Travel Med Infect Dis 2020;34:101623.

55 Tian S, Hu N, Lou J, et al. Characteristics of COVID-19 infection in Beijing. J Infect 2020;80:401-6.

56 Bernheim A, Mei X, Huang M, et al. Chest CT findings in coronavirus Disease-19 (COVID-19): relationship to duration of infection. Radiology 2020;295:200463.

57 Han $\mathrm{R}$, Huang $\mathrm{L}$, Jiang $\mathrm{H}$, et al. Early clinical and CT manifestations of coronavirus disease 2019 (COVID-19) pneumonia. AJR Am J Roentgenol 2020;215:338-43.

$58 \mathrm{Li} \mathrm{K}, \mathrm{Wu}$ J, Wu F, et al. The clinical and chest CT features associated with severe and critical COVID-19 pneumonia. Invest Radiol 2020;55:327-31.

$59 \mathrm{Xu} \mathrm{X,} \mathrm{Yu} \mathrm{C,} \mathrm{Qu} \mathrm{J,} \mathrm{et} \mathrm{al.} \mathrm{Imaging} \mathrm{and} \mathrm{clinical} \mathrm{features} \mathrm{of} \mathrm{patients} \mathrm{with}$ 2019 novel coronavirus SARS-CoV-2. Eur J Nucl Med Mol Imaging 2020;47:1275-80.

60 Liu K-C, Xu P, Lv W-F, et al. CT manifestations of coronavirus disease-2019: a retrospective analysis of 73 cases by disease severity. Eur J Radiol 2020;126:108941.

61 Xiong Y, Sun D, Liu Y, et al. Clinical and high-resolution CT features of the COVID-19 infection: comparison of the initial and follow-up changes. Invest Radiol 2020;55:332-9.

62 Huang C, Wang Y, Li X, et al. Clinical features of patients infected with 2019 novel coronavirus in Wuhan, China. Lancet 2020;395:497-506.

63 Chung M, Bernheim A, Mei X, et al. CT imaging features of 2019 novel coronavirus (2019-nCoV). Radiology 2020;295:202-7.

64 Cheng Z, Lu Y, Cao Q, et al. Clinical features and chest CT manifestations of coronavirus disease 2019 (COVID-19) in a single-center study in Shanghai, China. AJR Am J Roentgenol 2020;215:121-6

65 Dong X, Cao Y-Y, Lu X-X, et al. Eleven faces of coronavirus disease 2019. Allergy 2020;75:1699-709. 